\title{
Frequent ophthalmologic problems and visual development of preterm newborn infants
}

\author{
Rosa Maria Graziano, ${ }^{1}$ Cléa Rodrigues Leone ${ }^{2}$
}

\begin{abstract}
Objectives: To review the concepts of visual development and the major ocular abnormalities in preterm newborns. To emphasize the importance of preventive ophthalmologic examination and early treatment of ocular disorders.

Source of data: A review of published data.

Summary of the findings: Vision is one of the most important senses in the normal physical and cognitive development of children. Schoolchildren who were born preterm have impaired visual, motor and cognitive functions when compared to those of children born full term. This is more a consequence of central nervous system immaturity than of localized injuries to ocular and/ or cortical structures. The literature pinpoints retinopathy of prematurity, strabismus and refractive errors as the main ophthalmologic alterations resulting from prematurity. Retinopathy of prematurity is one of the main causes of preventable blindness in childhood. It is estimated that on average 562 children become blind each year in Brazil, which is a very high socioeconomic cost to result from a treatable disease. Children with visual deficiencies may be helped by programs of early visual stimulation in order to promote their environmental integration.

Conclusions: The recommendation is that every preterm newborn weighing less than $1,500 \mathrm{~g}$ and/or with a gestational age of less than 32 weeks should be monitored until complete retinal vascularization and that the first examination should be performed between the fourth and sixth weeks of life. We recommend ophthalmologic outpatients follow-up of all preterm newborns until two years of life with examinations twice yearly, and then, annually, in order to prevent amblyopia.
\end{abstract}

J Pediatr (Rio J). 2005;81(1 Suppl):S95-S100: Premature infant, retinopathy of prematurity, vision, ocular refraction, strabismus.

Depending on the degree of immaturity at birth, in preterm newborns (PTNB) the development and maturation of many different organs and systems should continue during the postnatal period in order that they are fully capacitated for insertion into the macro-environment, within a dynamic process that interacts with and defends them from this environment.

1. $\mathrm{PhD}$ at the School of Medicine of Universidade de São Paulo. Assistant physician, Ophthalmology Service, Hospital das Clínicas, School of Medicine, Universidade de São Paulo (USP). President of the Department of Ophthalmology of the Brazilian Pediatric Ophthalmology Society, São Paulo, SP, Brazil.

2. Associate professor, Department of Pediatrics, School of Medicine, Universidade de São Paulo (USP), São Paulo, SP, Brazil.

Suggested citation: Graziano RM, Leone CR. Frequent ophthalmologic problems and visual development of preterm newborn infants. J Pediatr (Rio J). 2005;81(1 Suppl):S95-S100.
Vision is one of the most important senses for the normal physical and cognitive development of children. Motor development and the capacity to communicate are prejudiced in children with visual deficiencies because gestures and social conduct are learnt through visual feedback. Early diagnosis of diseases, effective treatment and early visual stimulation programs can allow children to achieve greater interaction with their surroundings.

Certain basic concepts related to the eyes and the optic tracts are indispensable to understanding visual development and the most frequent ophthalmological diseases of PTNB.

\section{Anatomy of the eye and optic tracts}

The bulb of the eye is made up of three concentric tunics, with the outside one made up of the cornea and sclera. The second, the vascular tunic, is made up of the choroid, ciliary body and iris, and the inner, or nervous tunic, is the retina. 
The sclera or "white of the eye" is a fibrous layer. It is here that the extra-ocular muscles that move the eye are inserted. The cornea is the transparent part of the eye allowing the iris and pupil to be seen. The cornea and crystalline lens are the lenses that focus the image on the retina. Any alteration to the transparency of these structures will result in prejudiced image formation and consequently reduced visual acuity (VA) (Figure 1 ).

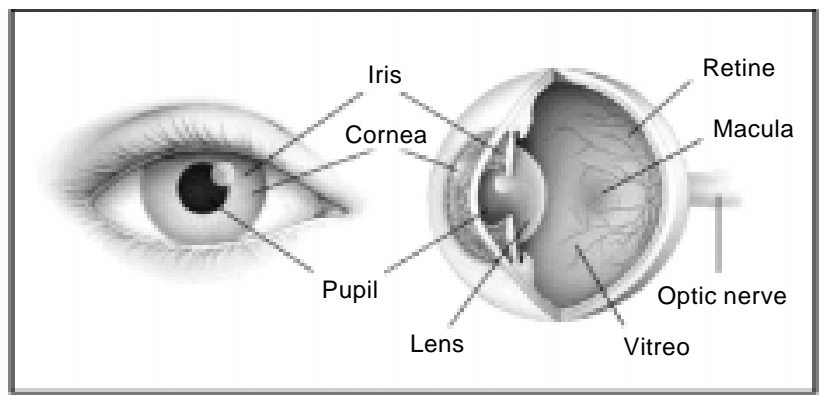

Figure 1 - Eye anatomy (schematic section)

Light enters the eye via the pupil and the image is focused on the retina by the lenses. Here the light is transformed into electrical impulses by the photoreceptors (cones and rods) and transmitted to the brain by the bipolar and ganglion cells. It is the axons of the ganglion cells that make up the optic nerve. Before reaching the occipital lobe, where these stimuli are decoded, the ganglion cells synapse at the lateral geniculate body.

\section{Growth of the eye and refractive errors}

The eye of a newborn child has an antero-posterior diameter (APD) of approximately $16 \mathrm{~mm}$ and should reach, by adulthood, $23 \mathrm{~mm}$. There are three phases to the growth of the eye. On average the eye will achieve an APD of 20.3 $\mathrm{mm}$ during the first 18 months of life, from 2 to 5 years it grows a further $1.1 \mathrm{~mm}$ and, from 5 to 13 , another $1.3 \mathrm{~mm}$. They eye always tends to emetropia (with no refractive errors) and, in order to compensate for the smaller APD at birth the cornea has a high power of refraction (47.6 diopters), which reduces progressively as the eye grows, reaching 42.5 diopters in adulthood. 1,2

Children born to full term have a slight tendency to hypermetropia. Population studies show that this hypermetropia tends to increase until 7 years of age and then there is a tendency to myopization until adulthood. Astigmatism is often associated with the degree of sphere.

Premature children are more often myopic. There is evidence that the development of the anterior segment of the eye is more "dragged-out" among premature children and they present cornea and crystalline lenses with greater refractive power, resulting in myopia. In cases where severe retinopathy of prematurity (ROP) is established, treatment results in structural damage that could lead to abnormalities in eye growth. ${ }^{1}$

\section{Visual development}

In order that visual development be normal, good anatomic and physiological conditions are necessary. Children need to "see" in order to develop their vision and, until VA is completely established, any obstacle to the formation of a clear image in both eyes, such as cataract, strabismus, anisometropia (a difference of more than three degrees between the refractive errors of the two eyes) or palpebral occlusion can lead to poor visual development, which will become irreversible if not treated in good time. Amblyopia is the term employed when the vision does not develop normally because of these problems. It is therefore important that divergences from normal development be identified and corrected as early as possible, with the first 3 months of life being a critical period in this process.

At birth children's vision is relatively poor, as a result of the immaturity of brain and retina structures related to vision and movement of the eyes. Newborn babies (NBs) do not generally exhibit aligned eyes during their first days of life, since monocular fixation will only be properly developed by 2 months, and stereopsis or binocular vision will be properly developed by between 3 and 7 months. It is rare for congenital esotropia to be diagnosed before 6 months and occasionally misaligned eyes before 6 months are not indicative of strabismus. A population study that assessed newborns during their first days of life found that approximately $30 \%$ of the NBs had aligned eyes, $70 \%$ had diverging eyes and less than $1 \%$ had converging eyes. ${ }^{3}$

Visual development is a complex mechanism, with great variations between the visual behavior of different children, but on average we find: ${ }^{1}$

The reflex that controls the pupil's reaction to light is present from 30 weeks' gestation and the eyeblink reflex at 2 to 5 months of life.

The structure of the fovea centralis begins to form at 3 to 4 weeks and is mature by 4 months (children can fix on objects and people by 1 to 2 months). The association between macular fixation and manual movements, i.e. the ability to grasp close objects, only develops after 4 months.

Depth vision, or stereopsis, can be observed between 3 and 7 months. For this function to be implanted it is necessary that the child has similar and correctly located images on the retina of each eye from birth. Therefore, if the child has a congenital cataract or anisometropia, this process will be compromised.

Sensitivity to contrast is well developed by 7 months and myelination of the optic nerve is complete between 7 months and 2 years.

The VA of an NB improves very quickly during the first 3 months of life and then more slowly. By 3-4 years it is believed that the visual system is completely developed, but it can still be molded until 8 to 10 years. From this point onwards treatment for amblyopia will have few results.

In school-aged children born premature, visual, motor and cognitive functions are prejudiced in comparison with children born to full term. ${ }^{4,5}$ This is due more to immaturity of the central nervous system than to injuries to ocular or cortical structures. ${ }^{5}$ 
When VA during the first year of life is assessed by sweep visual evoked potential it is found that VA development is significantly delayed in the PTNB subset when compared with fullterm children. There are not, however, statistical differences between the VA development velocities of PTNB subsets with gestational ages above and below 34 weeks and PTNB with normal and abnormal neuropsychomotor development. 6

When the visual development of premature children is being discussed there is no consensus on whether to use corrected gestational age or chronological age as parameters. In daily practice, there are no two children whose visual development is identical and we have observed great variation among preterms, oscillating between the two parameters.

The principle ophthalmologic abnormalities described in the literature as secondary to prematurity are ROP, strabismus and refractive errors. ${ }^{7,8}$ Preterms may also exhibit reduced VA because of cortical damage and glaucoma. Children that develop severe ROP also have a greater risk of suffering later retinal detachment. ${ }^{7}$

Graziano et al. performed an outpatients follow-up of PTNB and found that the prevalence of strabismus is higher among premature children. ${ }^{8}$ There was no statistical difference between a subset that did not develop ROP (13.63\%) and another that did develop ROP, but presented spontaneous involution (14\%). The subset of children requiring surgery, however, presented $30 \%$ strabismus, which is extremely elevated if we consider that children born to full term present strabismus in just $2 \%$ of cases. ${ }^{8,9}$ There were no statistical differences between the study groups and fullterm children with respect of refractive error although extreme refraction values were observed in the subset of children with ROP who required surgery. ${ }^{8,10}$

\section{ROP}

Retinopathy of prematurity is a vasoproliferative disease of the retina with multifactor etiology and which occurs in PTNB. It is one of the principal causes of preventable blindness in children. There is an acute phase in which normal vasculogenesis is interrupted and the immature retina suffers cellular proliferation and transformation. In the majority of children the retinopathy undergoes spontaneous involution, leaving no damage or mild scarring. Proliferative retinopathy may progress to a fibrotic scarring process and detachment of the retina.

In recent years new drugs and techniques have been introduced to treat these children, leading to reductions in perinatal mortality, the survival of very premature NBs and a proportional increase in the prevalence and severity of ROP.

It is difficult to determine the current number of children in Brazil who have visual deficiencies or blindness as a result of ROP. The I Workshop on ROP, which took place in Rio de Janeiro in 2002,11 assessed data from 16 ROP diagnosis and treatment programs and detected that around 7.5\% (5 to $10 \%$ ) of babies examined were affected by stage 3 Plus disease. Mean birth weight and gestational age were $948 \mathrm{~g}$ and 28.5 weeks, respectively.

It is calculated that every year around 15,000 preterms at risk of ROP survive, needing screening examinations for diagnosis. Assuming that $7.5 \%$ of these children will develop borderline disease and that $50 \%$ of these will go blind if untreated, we have an average of 562 blind children/year, at a high socio-economic cost, in particular since this is a treatable disease. ${ }^{11}$

\section{Pathophysiology}

The human retina has no vessels until the fourth month of intrauterine life, being fed by diffusion from vessels in the choroid. During the fourth month, fusiform cells, probably of mesenchymal origin, form a dense network of capillaries that grow from the optic nerve to the periphery of the retina. The photoreceptors also grow from the optic nerve to the periphery, with $80 \%$ reaching the ora serrata by 28 weeks' gestation. There is synchronization between the photoreceptors' progressive demand for oxygen and the development of the retinal vessels and which is stimulated by vascular endothelial growth factor (VEGF).

Thus ROP is related to the oxygen-regulated factor VEGF and also to factors that are not regulated by oxygen (insulinlike growth factor - IGF-1) which inhibit vascularization of the retina when at low levels and stimulate neovascularization of the retina at high levels. ${ }^{12,13}$

After premature birth, PTNB are subjected to hyperoxia which inhibits the production of VEGF. The administration of supplementary oxygen can lead to sustained hyperoxia, which in turn results in obliteration of vessels and the nonvascularization of the retina. With time, the metabolic demands of the growing eye increase and the unperfused peripheral area of the retina becomes hypoxic leading to VEGF overproduction and neovascularization of the retina. ${ }^{12}$

Insulin-like growth factor is necessary for the normal development of the retina. Low IGF-1 values in serum are related with later development of ROP. An IGF-1 assay taken at 30 to 33 weeks' postconceptional gestational age is predictive of the development of ROP (severe ROP: $25 \pm 2.41 \mu \mathrm{g} / \mathrm{l}$; moderate ROP: $29 \pm 1.76 \mu \mathrm{g} / \mathrm{l}$; no ROP: $33 \pm 1.72 \mu \mathrm{g} / \mathrm{l})$. The duration of the period during which IGF-1 levels are low is strongly correlated with the severity of ROP. In a prospective study, it was observed that, when the interval between birth and the day that IGF-1 reached $33 \mu \mathrm{g} / \mathrm{l}$ was $52 \pm 7.5$ days, severe ROP resulted, when this interval was $44 \pm 4.8$ days, ROP was moderate and when it was $23 \pm 2.6$ days, patients did not develop ROP. ${ }^{13}$

The majority of cases undergo spontaneous involution, but severe retinopathy can progress to detachment of the retina.

\section{Risk factors}

The principal risk factors for ROP are prematurity and low birth weight. Other risk factors involved are: fluctuations in oxygen levels during the first weeks of life, being small for gestational age, intraventricular hemorrhage, blood 
transfusions, persistent ductus arteriosus, Apgar score below 7 and certain maternal risk factors. ${ }^{13-15}$

\section{International Retinopathy of Prematurity Classification 16}

The classification of ROP is based on three parameters: location, extension and stage:

Location is diagnosed by dividing the retina into three zones, with zone 1 being the most central and where the disease is most severe (Figure 2). The extent of vascular involvement is registered by the number of hours as on a clock face. Table 1 lists the stages of ROP together with the treatment and follow-up recommended for each one. 17-19

The stages of ROP are progressively more serious, from stage 1 (mild) to 5 (most severe). We always assess a child's ROP by the most severe stage that it reaches. Stages 1 and 2, when affecting zone 3, recover spontaneously, without leaving retinal sequelae or, if these do occur they do not greatly prejudice vision. Any disease in zone 1 is severe and the presence of engorged vessels is one of the most valued findings for indicating surgery and classifying disease severity. Stage 3 ROP is characterized by intense fibrovascular proliferation and, when present in 5 contiguous hours or 8 separated hours in zone 1 or 2 with venous engorgement, characterizes threshold disease, which is the classical indication for surgical treatment with ablation of the avascular retina with photocoagulation or cryotherapy. If not treated at this stage, approximately $50 \%$ of children will progress to stages 4 and 5 with detachment of the retina and major visual compromise. ${ }^{17-19}$

\section{Who should be examined and when}

The Royal College of Ophthalmology in the United Kingdom recommend examining babies whose birth weights are less than or equal to $1,500 \mathrm{~g}$ and/or gestational ages are less than or equal to 31 weeks, with the first examination to be performed between the sixth and seventh week of life. ${ }^{20}$ In the USA, the first examination is performed between the

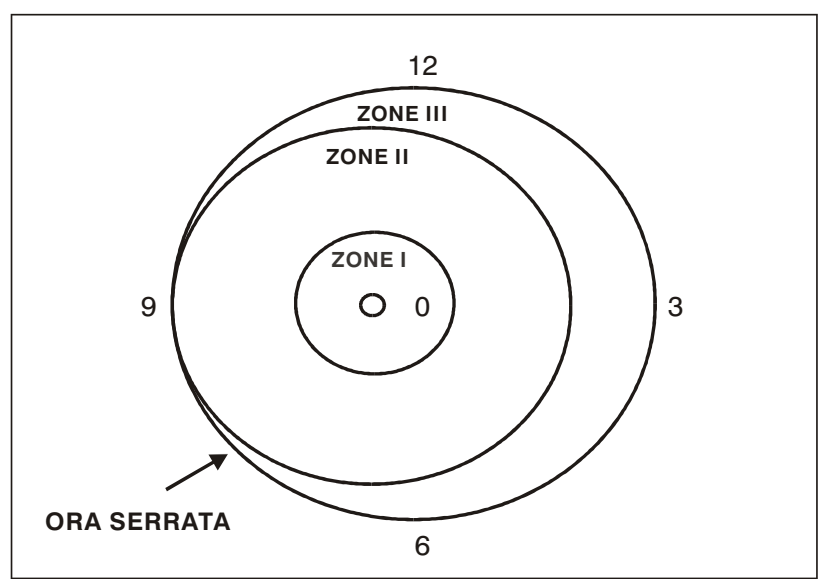

Figure 2 - Schematic representation of Retinopathy of Prematurity zones - International Classification of ROP

Table 1 - Classification of retinopathy of prematurity and treatment recommended for each stage

\begin{tabular}{|c|c|c|}
\hline Stage & Retina alterations & Treatment - follow-up \\
\hline Stage 1 & $\begin{array}{l}\text { White line between vascular } \\
\text { and avascular retina }\end{array}$ & Weekly observation \\
\hline Stage 2 & Prominent ridge & Weekly observation \\
\hline Stage 3 & Fibrovascular proliferation from the ridge & Observation every 2 days \\
\hline Stage 4 & $\begin{array}{l}\text { Proliferation may cause partial retinal detachment } \\
\text { ( } 4 \mathrm{a} \text { if the fovea is spared and } 4 \mathrm{~b} \text { if the fovea is involved) }\end{array}$ & $\begin{array}{l}\text { Cyrocoagulation }+ \\
\text { scleral buckle and/or } \\
\text { pars plana vitrectomy }\end{array}$ \\
\hline Stage 5 & $\begin{array}{l}\text { Total retinal detachment (funnel shaped either open } \\
\text { or closed at the anterior and posterior ends) }\end{array}$ & Pars plana vitrectomy \\
\hline Threshold disease & $\begin{array}{l}\text { Stage } 3 \text { retinopathy with plus disease } \\
\text { across } 5 \text { contiguous hours or } 8 \text { separated hours } \\
\text { of zone } 1 \text { or } 2 \text { (arteriolar dilation and venodilation) }\end{array}$ & $\begin{array}{l}\text { Photocoagulation or } \\
\text { cryotherapy of the } \\
\text { avascular retina }\end{array}$ \\
\hline Pre-threshold disease type 1 & $\begin{array}{l}\text { Zone } 1 \text { - any stage with plus disease } \\
\text { Zone } 1 \text { - stage } 3 \text { wihtout plus disease } \\
\text { Zone } 2 \text { - stage } 2 \text { or } 3 \text { with plus disease }\end{array}$ & $\begin{array}{l}\text { Photocoagulation or } \\
\text { cryocoagulation of the } \\
\text { avascular retina }\end{array}$ \\
\hline Pre-threshold disease type 2 & $\begin{array}{l}\text { Zone } 1 \text { - stage } 1 \text { or } 2 \text { without plus disease } \\
\text { Zone } 2 \text { - stage } 3 \text { without plus disease }\end{array}$ & Observation every 2 days \\
\hline
\end{tabular}


fourth and sixth weeks of life and examinations are indicated for NBs whose birth weights are less than or equal to $1,500 \mathrm{~g}$ or gestational ages are above 28 weeks and also for babies with birth weights of more than $1,500 \mathrm{~g}$, but unstable clinical condition. 21

Based on data presented at the I Workshop on ROP, 11 the Brazilian Society of Pediatrics (Sociedade Brasileira de Pediatria), the Brazilian Pediatric Ophthalmology Society (Sociedade Brasileira de Oftalmologia Pediátrica) and the Brazilian Ophthalmology Council (Conselho Brasileiro de Oftalmologia) recommended that NBs be examined if birth weight is $<1,500 \mathrm{~g}$ and/or gestational age is $<32$ weeks. The first exam should be performed between four and six weeks of life and subsequent examinations every 1 or 2 weeks, depending on the findings from the first examination, until the retina has completed vascularization or until the disease has reached stage 3 Plus with indication for surgery. In addition to these indications NBs should be examined in the presence of risk factors such as respiratory distress syndrome; sepsis; blood transfusions; multiple pregnancy and intraventricular hemorrhage.

The parents of children presenting ROP should be informed of its nature and of the possible consequences. After discharge from the maternity unit, the parents should be made aware of the need for outpatients follow-up, since their children will present an increased risk of strabismus, refractive errors and amblyopia, in addition to often not having reached complete vascularization of the retina. An American study 22 showed that $75 \%$ of children will attend an outpatients examination that has been booked by the maternity unit staff and just $37 \%$ will attend an appointment made by the parents. Therefore there must be strict cooperation between parents, neonatologists and ophthalmologists.

We recommend that premature children, even those who did not develop ROP, be examined at 6 months (to check for congenital strabismus) and at 12,18 and 24 months and then annually to test for strabismus, refractive errors, anisometropia and amblyopia.

Children with visual deficiencies should be referred to an ophthalmologist, since the prescription of optical devices and an early program of visual stimulation will allow greater integration with their environment and a life that is closer to normal.

\section{Treatment}

When ROP reaches stage 3 Plus across 5 contiguous hours or 8 separated hours of zone 1 or 2 (threshold disease), then ablation of the avascular retina is indicated with photocoagulation or cryotherapy. More recently, the indication for photocoagulation or cryotherapy treatment has been extended to pre-threshold type 1 . The Multicenter Trial of Cryotherapy for Retinopathy of Prematurity Cooperative Group - CRYO-ROP17,18 and Early Treatment for Retinopathy of Prematurity - ETROP ${ }^{19}$ have demonstrated that treatment is associated with a reduction in the risk of poor vision. Laser treatment has become a more accepted option as presenting less operative complications and longterm ocular sequelae. ${ }^{23-25}$ Surgery with cryocoagulation of the retina is an option when opaque media are present and is also a faster procedure which is a positive factor for children at high risk from anesthetics. Vitrectomy surgery for stage 5 cases offers unsatisfactory functional and anatomic results although good results have been reported at stage $4.26,27$

\section{Differential diagnosis}

Norrie syndrome (recessive, sex-linked) and familial exudative vitreoretinopathy (autosomal, dominant) are anomalies of retina formation and have a funduscopic appearance very similar to ROP in fullterm children.

\section{New horizons for ROP}

The explosion in telecommunications and digital cameras with the capacity to capture panoramic images of the fundus of the eye mean that images can be assessed by specialists at distance. Schwartz et al. ${ }^{28}$ using a RetCam 120, compared local diagnosis with that obtained via telemedicine. Abnormalities of the posterior pole, and venous engorgement were identified in $95 \%$ of eyes and stages 3.4; and 5 in $89 \%$.

Better understanding of the pathophysiology of this disease will permit the identification of severe cases and the prevention of the disease by means of systematic assays of growth factors and other factors involved in the angiogenesis of the retina.

The eye has special characteristics for the study of genetic therapy: ROP is a disease that takes place over a short period of time, the child is immunodepressed during this period and will not recognize the viral vector and it is possible to view the disease process by means of fundoscopy. ${ }^{29}$ There are real expectations that genetic therapy can modulate the synthesis of cytokines and growth factors involved in ROP pathophysiology, developing a new, better treatment for ROP.

At the national level there is a movement of ophthalmologists and pediatricians for mapping ROP during its acute and scarring phases. The implementation of a standard ophthalmological examination form, of national databases and a diagnostic screening and treatment program in several Brazilian cities are recent actions. It is hoped that, in obtaining a better understanding of the dimensions of the ROP problem in Brazil, it will be possible to establish prevention and treatment strategies. Notwithstanding, more effective control of this disease will only take be achieved if the teams that care for PTNB are made aware that prevention is the most effective measure.

\section{References}

1. Wright KW, Spiegel PH. Pediatric Ophthalmology and Strabismus. 1st ed. St Louis: Mosby; 1999. p. 1-10.

2. Snir M, Friling R, Weinberger D, Sherf I, Axer-Siegel R. Refraction and keratometry in 40 week old premature (corrected age) and term infants. Br J Ophthalmol. 2004;88:900-4. 
3. Wright KW, Spiegel PH. Pediatric Ophthalmology and Strabismus. 1st ed. St Louis: Mosby; 1999. p. 231.

4. O'Connor AR, Stephenson TJ, Johnson A, Tobin MJ, Ratib S, Moseley $\mathrm{M}$, et al. Visual function in low birthweight children. $\mathrm{Br}$ J Ophthalmol. 2004;88:1149-53.

5. Larsson E, Martin L, Holmstrom G. Peripheral and central visual fields in 11-year-old children who had been born prematurely and at term. J Pediatr Ophthalmol Strabismus. 2004;41:39-45.

6. Haro FM, Salomão SR, Berezovsky A, Costa MF, Muñoz EH, Cardoso MR. Desenvolvimento da acuidade visual de prematuros durante o primeiro ano de vida pelo registro dos potenciais visuais evocados de varredura. Tema livre apresentado no XVIII Congresso Brasileiro de Perinatologia; 2004, novembro 14-16; São Paulo, Brasil.

7. Repka MX. Ophthalmological problems of the premature infant. Ment Retard Dev Disabil Res Rev. 2002;8:249-57.

8. Graziano RM, Carricondo P, Warde S, Dotto P, Bigolin S, Sadeck LS, et al. Prevalência de estrabismo, erros de refração e seqüelas fundoscópicas de retinopatia da prematuridade em recém nascidos prematuros de muito baixo peso no seguimento ambulatorial de 5 anos. Tema livre apresentado no XXXII Congresso Brasileiro de Oftalmologia; 2003, setembro 10-13; Salvador.

9. Taylor D, Hoyt C. Practical Paediatric Ophthalmology. 1st ed. Cambridge: Blackwell Science; 1997. p. 16.

10. Taylor D, Hoyt C. Practical Paediatric Ophthalmology. 1st ed. Cambridge: Blackwell Science; 1997. p. 9.

11. Relatório do I Workshop de Retinopatia da Prematuridade, 2002. Rio de Janeiro, Brasil Documento não publicado.

12. Pierce EA, Foley ED, Smith LE. Regulation of vascular endothelial growth factor by oxygen in a model of retinopathy of prematurity. Arch Ophthalmol. 1996;114:1219-28.

13. Hellstrom A, Engstrom E, Hard AL, Albertsson-Wikland $K$, Carlsson B, Niklasson A, et al. Postnatal serum insulin-like growth factor I deficiency is associated with retinopathy of prematurity and other complications of premature birth. Pediatrics. 2003;112:1016-20.

14. Kornacka MK, Tupieka A, Czajka I, Gajewska M, Golebiewska E. Tissue and blood oxygenation in newborns $<1250 \mathrm{~g}$ and incidence of ROP. Ginekol Pol. 2003;74:538-44.

15. Graziano RM. Retinopatia da prematuridade: contribuição ao estudo da ocorrência e análise dos fatores de risco [tese]. São Paulo (SP): Faculdade de Medicina da Universidade de São Paulo; 1994.

16. Committee for the classification of retinopathy of prematurity. An International Classification of Retinopathy of Prematurity. Arch Ophthalmol. 1984;102:1130-5.

17. Cryotherapy for Retinopathy of Prematurity Cooperative Group. Multicenter trial of cryotherapy for retinopathy of prematurity. Preliminary results. Arch Ophthalmol. 1988;106:471-9.
18. Cryotherapy for Retinopathy of Prematurity Cooperative Group. Multicenter trial of cryotherapy for retinopathy of prematurity. $31 / 2$ year outcome - structure and function. Arch Ophthalmol. $1993 ; 111: 339-44$.

19. Early Treatment for Retinopathy of Prematurity Cooperative Group. Revised Indications for the Treatment of Retinopathy of Prematurity. Arch Ophthalmol. 2003;121:1684-96.

20. Royal College of Ophthalmologists and British Association of Perinatal Medicine. Retinopathy of Prematurity. Guidelines for screening and treatment: the report of a joint working party. Early Hum Dev. 1996;46:239-58.

21. Joint statement of the American Academy of Pediatrics, the American Association for Pediatric Ophthalmology and Strabismus, and the American Academy of Ophthalmology: screening examination of premature infants for retinopathy of prematurity. Pediatrics. 2001;108:809-11.

22. Compliance with outpatient follow-up recommendations for infants at risk for retinopathy of prematurity. J AAPOS. 2000;4:282-6.

23. Hunter DJ, Repka MX. Diode laser photocoagulation for threshold retinopathy of prematurity. Ophthalmology. 1993;100:238-44.

24. White JE, Repka MX. Randomized comparison of diode laser photocoagulation versus cryotherapy for threshold retinopathy of prematurity: 3 year outcome. J Pediatr Ophthalmol Strabismus. 1997;34:83-7.

25. McNamara JA, Tasman W, Vander JF, Brown GC. Diode laser photocoagulation for retinopathy of prematurity. Preliminary results. Arch Ophthalmol. 1992;110:1714-6.

26. Quinn GE, Dobson V, Barr CC, Davis BR, Palmer EA, Robertson $\mathrm{J}$, et al. Visual acuity of eyes after vitrectomy for retinopathy of prematurity: follow-up at $51 / 2$ years. Ophthalmology. 1996; 103:595-600.

27. Trese MT, Droste PJ. Long term postoperative results of a consecutive series of stage 4 and 5 retinopathy of prematurity. Ophthalmology. 1998;105:992-7.

28. Schwartz S, Harrison A, Ferrone P. Telemedical evaluation and management of retinopathy of prematurity using a fiberoptic digital fundus câmera. Ophthalmology. 2000;107:25-8.

29. Good W, Gendron R. Gene therapy for retinopathy of prematurity: the eye is a window to the future. $\mathrm{Br}$ J Ophthalmol. 2001;85:891-3.

\section{Correspondence:}

Rosa Maria Graziano

Av. Ibirapuera, 1761

CEP 04029-100 - São Paulo, SP

Brazil

Phone: +55 (11) 5052.5622 / 5051.3704 / 5055.0212

E-mail: rmgraziano@terra.com.br 